\title{
HOW TO INVESTIGATE PERCEPTUAL PROJECTION: A Commentary on Pereira Jr., "The Projective Theory OF CONSCIOUSNESS: FROM NEUROSCIENCE TO PHILOSOPHICAL PSYCHOLOGY"
}

\author{
Max Velmans ${ }^{1}$
}

\begin{abstract}
This commentary focuses on the scientific status of perceptual projection-a central feature of Pereira's projective theory of consciousness. In his target article, he draws on my own earlier work to develop an explanatory framework for integrating first-person viewable conscious experience with the third-person viewable neural correlates and antecedent causes that form conscious experience into a bipolar structure that contains both a sense of self (created by interoceptive projective processes) and a sense of the world (created by exteroceptive projective processes). I stress that perceptual projection is a psychological effect (not an explanation for that effect) and list many of the ways it has been studied within experimental psychology, for example in studies of depth perception in vision and audition and experiences of depth arising from cues arranged on two-dimensional surfaces in stereoscopic pictures, $3 \mathrm{D}$ cinemas, holograms, and virtual realities. I then juxtapose Pereira's explanatory model with two other models that have similar aims and background assumptions but different orientations, Trehub's Retinoid model, which focuses largely on the neural functioning of the visual system, and Rudrauf et al's Projective Consciousness Model, which draws largely on projective geometries to specify the requirements of organisms that need to navigate a three-dimensional world, and how these might be implemented in human information processing. Together, these models illustrate both converging and diverging approaches to understanding the role of projective processes in human consciousness.
\end{abstract}

KEY words: Perceptual projection. Projective theory of consciousness. Retinoid model. Phenomenology of consciousness. Phenomenal world.

In his target article, Pereira suggests a broad explanatory framework for integrating the phenomenology of human conscious experience (viewed from a first-person perspective) with its third-person viewable neural correlates

${ }_{1}$ Professor Emeritus, Department of Psychology, Goldsmiths, University of London, New Cross, London - England. E-mail: m.velmans@gold.ac.uk

http://dx.doi.org/10.1590/0101-3173.2018.v41esp.12.p233

\section{(i)}


and antecedent preconscious mental processing. Although the contents of consciousness are indefinitely varied, there are, he notes, some enduring structures:

The structure of consciousness was philosophically conceived a century ago (Husserl, 1913) as consisting of a subjective pole, the bearer of experiences, and an objective pole composed of experienced contents. In more recent formulations, Nagel (1974) refers to a "point of view", in which qualitative experiences are anchored, while Velmans (1990; 1993 ; 2009; 2017) understands that phenomenal content is composed of mental representations "projected" to the space external to the brains that constructs them. [...] How to relate this bipolar structure with the results of neuroscience? I propose the notion of projection (also used by Williford et al., 2012) as a bridge principle connecting the neurobiological systems of knowing, feeling and acting with the bipolar structure. The projective process is considered responsible for the generation of the sense of self and the sense of the world, composing an informational phenomenal field generated by the nervous system and experienced in the first-person perspective. (PEREIRA JR, 2018, p. 200, my italics).

\section{WHAT IS PERCEPTUAL PROJECTION?}

In my own writings, for example in Velmans (1990, 2009), I stress that perceptual projection is a common, readily observable, psychological effect produced by preconscious mental processes. This experienced print, for example, seems to be out-there on this page along with the rest of the external, three-dimensional, phenomenal world. Given that preconscious processes within the brain, interacting with events in the external world, produce consciously experienced events that may be subjectively located and extended in the phenomenal space beyond the brain, how does this phenomenology get to be out-there?

Mysterious though perceptual projection might seem, it has been widely investigated (under different names) by psychological science. For example:

There is convincing evidence that the experience of depth is, in part, a construction of the mind/brain ... in cases of depth perception arising from cues arranged on two-dimensional surfaces in stereoscopic pictures, 3D cinemas, holograms, and virtual realities - and I have reviewed scientific evidence for perceptual projection in various other sense modalities in chapter 6, and in more detail in Velmans (1990). One can also study underlying processes such as the perception of distance and location in space-standard topics in the psychology of perception that 
one can find in any introductory psychology textbook. One can study the cues, or information in the light that contribute to depth perception (Hershenson, 1998), one can study the neural structures that support it (e.g. Goodale \& Milner, 2004; Goodale, 2007) and one can study the various instances where depth perception breaks down (Robertson, 2004). One can also study how the judged metrics of phenomenal space relate to physical measurements of space (e.g. Lehar, 2003) and how both of these relate to neural state space. Given that neural state space is (by definition) in the brain, and that phenomenal state space is [...] mostly outside the brain, an understanding of how neural state space relates to phenomenal state space would also provide a topology of perceptual projection. (VELMANS, 2009, p. 162).

A fuller understanding of perceptual projection also offers a more unified understanding of a wide range of phenomena experienced to have both location and extension, including phenomena as diverse as lucid dreams, hallucinations, eidetic imagery, the creation of virtual realities, the construction of a body image, and the normal perception of events in threedimensional space. Accepting perceptual projection as a normal effect (when perceptual processes form representations of events in the world) also makes it easier to understand what happens in artificial or pathological or situations. For example, three-dimensional virtual worlds can be understood to arise from artificial stimulation of the same projective processes that create normal, phenomenal worlds. Hallucinations can be understood to result from mental models that erroneously project information that has an internal rather than an external origin (consequent on a breakdown of the usually reliable modelling of internal versus external events). And projection, transference and counter-transference of the kinds that arise in therapeutic interactions can be understood as similar internal/external confusions where information about one's own feelings, thoughts or past experiences are bound into one's projected experience of another human being. As the processes that achieve "binding" and "projection" operate preconsciously, one literally experiences others to manifest the traits and qualities which in reality are one's own. (VELMANS, 2009, p. 163)

Although studies of these varied phenomena contribute to our understanding of the cues and processes that contribute to projective effects, they do not fully explain how proximal neural causes within the brain support experienced events that seem to be outside the brain. For this, we need an explanatory model—and no adequate explanatory model currently 
exists. Virtual realities and projection holograms provide tempting analogies (VELMANS, 1998, 2009). In so far as virtual realities generate perceived $3 \mathrm{D}$ worlds (in the absence of real ones) they provide an existence proof for projective psychological effects and provide creative ways of studying how information in the light provides cues on which projective processes operate. Projection holograms provide a tempting analogy for how information encoded on a $2 \mathrm{D}$ surface can be perceived as a $3 \mathrm{D}$ object in front of that surface, when viewed from an appropriate perspective. However, there is little convincing evidence that there is, literally, a "neural projection hologram" in the brain. Given the absence of an adequate explanation, the emergence of scientific models that both respect the $3 \mathrm{D}$ phenomenology of conscious experiences and provide a guide to projective neural processes that support them, is a welcome development.

\section{THE PHENOMENAL WORLD THOUGHT OF A BI-POLAR STRUCTURE}

In his paper, Pereira lists various additional investigative approaches to understanding projective processes, with (in principle) testable predictions that might reveal their underlying mechanisms. For example, by way of an elaboration to my suggestion that phenomenal space and its directly associated neural correlates encode identical information (about the world) that is formatted in different ways, Pereira adds the important point that these spaces are typically composed of a subjective pole (the sense of self) and an objective pole (the sense of the world), thereby forming a bipolar structure. The same point has also been developed in depth by Trehub $(1977,2001,2007)$ in his retinoid model of visual perception and, more recently, in the projective geometries explored by Rudrauf et al. (2017). However, the explanatory models they use differ both in orientation and detail.

Pereira suggest that this subjective versus objective polarity arises from two forms of projection - an interoceptive projection that constructs a sense of self, and an exteroceptive projection that constructs a sense of the world. The subjective pole is conceived as the "attractor" in the dynamics of sensory, emotional and affective systems of the living body, generated in the feeling history of the individual, and projected as an invariant "identity" in time (experienced as the sense of self). The objective pole, or sense of the world, is the projection of representations from the nervous system to its extensions related to the homeostasis and control of the body, which include neuro-muscular 
junctions, kinaesthetic sensors in muscles, and the cardiac and enteric nervous systems. Following Mitterauer (2013), Pereira then goes on to suggest some underlying mechanisms involving two kinds of interacting, neurobiological signaling networks: astroglial (supporting waves of feeling in living tissue) and mental representations in neuronal spiking patterns (supporting a sense of the world). Both of these operate unconsciously to support what Pereira refers to as an extended conscious field - his term for what we normally think of as the conscious, phenomenal world that includes an "inner" sense of self as well as a three-dimensional extended body and a world extended beyond the body surface.

Trehub, by contrast, develops a detailed model of how the brain constructs a representation of egocentric space around a sense of self based primarily on the structural and dynamic properties of layered cells and their projections within the visual system. This "retinoid" system, in turn, forms part of a larger neuro-cognitive model that is able to form many other useful perceptual and higher cognitive functions.

As Trehub observes:

We cannot imagine our own behavior without an awareness at the same time of a 3D space around us within which our behavior occurs. One of the distinguishing characteristics of humans is the ability to think of future situations and to plan ahead. We not only make mental representations of the existing layout of salient objects in our immediate spatial environment, but we are also able to "picture" the structure of hypothetical environments which may contain different objects in different locations. The self is the indispensable object that must be represented in our sensible space when we adapt our behavior to current circumstances, when we contemplate our behavioral choices, and when we plan for future contingencies. What we must foresee and what we must do occur in a $3 \mathrm{D}$ space surrounding a point of reference corresponding to our selves. If we are to understand the biophysical basis of self, then we must first give a plausible neuronal account of how the human brain is able to represent an object-filled space from an egocentric perspective. (TREHUB, 2007, p. 311).

By what biologically plausible means can the human brain create the diversity of veridical and hypothetical models/representations claimed above? I argue that (1) there is a system of mechanisms in the brain whose minimal properties can be specified and which can be demonstrated to have the competence to create such models, (2) that these neuronal mechanisms provide an internal structural analog of 3D space within which all phenomenal events are represented, and (3) that the system 
utilizes a compact and dynamic neuronal center which represents the self within the brain's analog of 3D space. (TREHUB, 2007, p. 311).

Trehub $(1991,2007)$ goes on to give a detailed account of how such spatial relationships might be encoded in a subset of retinoid neurodynamics including a model of depth perception and stereoscopic vision with both testable elements and predictions that place it squarely within the domain of normal science.

More recently, Rudrauf et al have developed a mathematical, projective consciousness model of how the brain constructs a three-dimensional model of the sensory world in which they posit projective geometry as a

necessary form of the generative model that must be deployed by any conscious organism that navigates a three-dimensional world. Put simply, to produce generalizable and veridical predictions, the internal models used by our brain must recapitulate the formal geometry of the world we are trying to make predictions about (from situated standpoints). In this setting, the projective consciousness model (PCM) regards projective geometry (in three dimensions) as the optimal geometry for situated inferences to the best explanation regarding sensory impressions. (RUDRAUF et al., 2017, p. 108).

As with the other theories mentioned above, their theory is grounded, in the first instance, in conscious phenomenology, and they develop a form of indirect realism in which phenomenal space is thought of as thought of as a biologically useful, projective representation of the world, not to be confused with the world itself (see also Velmans, 1990, 2009):

Investigations into the phenomenology of consciousness have emphasized that consciousness is grounded in a subjective standpoint and a space of sorts, using the basic schematics of a subject-object opposition and a relation between a center and a periphery [...] Spatiality is a pervasive aspect of subjective experience. When one closes one's eyes in a silent room, under normal conditions, one experiences a "lived space", to adopt a term of art commonly used in the phenomenological tradition, the sense of a 3-dimensional surrounding space that is invariant even as the state of the outside world constantly changes. We find such a space in both waking consciousness and in dream. It seems central to conscious experience in general, to the way it represents a world in three dimensions, in which we locate ourselves and from which we perceive, imagine, and plan action [...] In this context, the particular 
"way" such a space appears is considered as an immanent structure of the subjective conscious experience we "live through", and to which we have phenomenological access; it is not a feature of the world represented [...] (it only secondarily becomes itself an object of representation, something to which our attention can be drawn, just as one does not normally notice one's hand in hammering, though one can). As a first approximation, lived space can be said to feature, by default, a primarily egocentric representation of space, defining a peri-personal and an extrapersonal environment in relation to a body, and oriented along directions of perception and action [...] lived space ought not be considered a direct representation of the intrinsic spatial structure of the world, and can be conceived as an adaptive simulation, "user interface", projection or controlled "hallucination" that is actively constructed by the brain in real-time [...] Experientially, outside of pathological conditions, it engenders an illusion of direct realism, (i.e., of being conscious of the world itself directly) [...] which is probably a necessary condition for effectively representing our real environment and acting within it. But dreams, imagination, hallucinations, out of body experiences (OBEs), sensory substitution, vertigo, and various neurological syndromes, provide compelling evidence that our lived, moment-by-moment representation and subjective experience of ambient physical space is the construction of a virtual world. In fact, the normal, robust, ongoing conscious experience of co-localization in space of one's subjective point of view and of one's own body is contingent upon a process of multisensory inference, and reflects a dynamical balance in sensorimotor calibration. (RUDRAUF et al., 2017, p. 108).

They then go on to develop a formal, projective, geometric model of how egocentric space is experienced, following an approach that is analogous to the methods used for 3-dimensional mapping of objects from sets of 2-dimensional pictures that are widely used in architecture, virtual reality, computer graphic imaging and computer vision, drawing on the principle that,

In lived space, objects, points of view and their relations of incidence are represented with the shape of 3-dimensional projections in perspective, along certain directions, from a certain standpoint; parallel lines converge on an implicit or explicit horizon at infinity. It is through the lens of this inherently perspectival geometry that a world of transcendent 3-dimensional objects in Euclidean space existing in independence of any particular perspectives (whose sizes remain the same irrespective of distance) is consciously experienced. (RUDRAUF et al., 2017, p. 110). 
And, as do Trehub, and Pereira, they treat these projective processes as a front end of human adaptive functioning that feeds information into higherorder cognitive-inferential processes that, ultimately, guide behaviour-and give suggestions about which neural structures are likely to be involved. In particular,

the model predicts that the brain should embed two main engines that are hierarchically coupled [...] (1) an inference engine grouping higher levels of control concerned with homeostasis, emotion, memory, language and executive functions, or more generally personal relevance; and (2) a lower (sensorimotor) projective geometry engine, relying on multisensory integration and motor programming and concerned with representing the world and the body in the world. (RUDRAUF et al., 2017, p.126).

Broadly viewed, Pereira's orientation is more philosophical, Trehub's neurophysiological, and Rudrauf et al, mathematical, but their models converge in how they conceptualise the phenomenology of conscious experience, the role of projective processes in cognitive functioning and behaviour, and the need to relate conscious phenomenology to its supporting neural functioning. As these models are complex, an evaluation of their fit with the evidence is beyond the scope of this brief commentary. Nor is there space to compare or evaluate their relative merits in detail. However, even this brief presentation should make it apparent that investigations of perceptual projection are forming into a productive, research programme that may provide central insights into the nature of human consciousness.

VELMANS, M. Como investigar a projeção perceptual: um comentário a Pereira Jr., "A teoria projetiva da consciência: da neurociência à psicologia filosófica". Trans/Form/Ação, Marília, v. 41, p. 233-242, 2018. Edição Especial.

Resumo: Este comentário enfoca o status científico da projeção perceptiva - uma característica central da teoria da consciência de Pereira. Em seu artigo alvo, ele recorre ao meu trabalho anterior para desenvolver uma estrutura explicativa para integrar a experiência consciente visível em primeira pessoa com os correlatos neurais visíveis de terceira pessoa e as causas antecedentes que formam a experiência consciente em uma estrutura bipolar que contém tanto um sentido de eu (criado por processos projetivos interoceptivos) e um sentido do mundo (criado por processos projetivos exteroceptivos). Enfatizo que a projeção perceptiva é um efeito psicológico (e não uma explicação para esse efeito) e relaciono modalidades de seu estudo na psicologia experimental, por exemplo em estudos de percepção 
de profundidade em visão e audição, experiências de profundidade em superfícies bidimensionais em imagens estereoscópicas, cinemas 3D, hologramas e realidades virtuais. Eu então justaponho o modelo explicativo de Pereira com dois outros modelos que têm objetivos e suposiçóes similares, mas orientaçóes diferentes, o modelo do sistema retinóide de Trehub, que se concentra principalmente no funcionamento neural do sistema visual, e o modelo de consciência projetiva de Rudrauf et al., que estabelece raciocínios geométricos para especificar os requisitos de organismos que precisam navegar em um mundo tridimensional, e como eles podem ser implementados no processamento de informação no contexto humano. Juntos, esses modelos ilustram abordagens convergentes e divergentes para compreender o papel dos processos projetivos na consciência humana.

Palavras-chave: Projeção perceptual. Teoria projetiva da consciência. Modelo retinoide. Fenomenologia da consciência. Mundo fenomenal.

\section{REFERENCES}

GOODALE, M. A. Duplex vision: separate cortical pathways for conscious perception and the control of action. In: VELMANS, M.; SCHNEIDER, S. (ed.). The Blackwell Companion to Consciousness. Oxford: Blackwell, 2007. p 616-627.

GOODALE, M. A.; MILNER, A. D. Sight unseen: an exploration of conscious and unconscious vision. New York: Oxford University Press, 2004.

HERSHENSON, M. Visual space perception. Cambridge: Mass.: MIT Press, 1998.

HUSSERL, E. Ideas: general introduction to pure phenomenology. Translation by F. Kersten. Dordrecht: Kluwer Academic, 1913.

LEHAR, S. Gestalt isomorphism and the primacy of subjective conscious experience: a gestalt bubble model. Behavioral and Brain Sciences, v. 26, n. 4, p. 375-444, 2003.

MITTERAUER, B. The proemial synapse: consciousness-generating glial-neuronal units. In: PEREIRA JR., A.; LEHMANN, D. (ed.). The unity of mind, brain and world: current perspectives on a science of consciousness. Cambridge-UK: Cambridge University Press, 2013. p. 233-264.

NAGEL, T. What is it like to be a bat? Philos. Rev., v. 83, n. 4, p. 435-450, 1974.

PEREIRA JR, A. The projective theory of consciousness: from neuroscience to philosophical psychology. Trans/Form/Ação, v. 41, n. especial, 2018, p. 199-232.

ROBERTSON, L. Space, objects, minds, and brains. New York: Psychology Press, 2004.

RUDRAUF, D. et al. A mathematical model of embodied consciousness. J. Theor. Biol., v. 428, p. 106-131, 2017.

TREHUB, A. Neuronal models for cognitive processes: networks for learning, perception and imagination. J. Theor. Biol., v. 65, p. 141-169, 1977.

. The cognitive brain. Cambridge, Mass.: MIT Press, 2001. 
Space, self and the theatre of consciousness. Consciousness and Cognition, v. 16, n. 2, p. 310-330, 2007.

VELMANS, M. Consciousness, brain and the physical world. Philosophical Psychology, v. 3, n. 1, p. 77-99, 1990.

. A reflexive science of consciousness. In: BOCK, G.; MARSH, J. (ed.).

Experimental and theoretical studies of consciousness. Chichester: John Wiley, 1993. p. 81-99.

. Physical, psychological and virtual realities. In: WOOD, J. (ed.). The virtual embodied. London: Routledge, 1998. p. 45-60.

. Understanding consciousness. 2nd ed. London: Routledge, 2009.

What and where are conscious experiences? Dualism, reductionism and reflexive monism. In: ALMQVIST, K.; HAAG, A. (ed.). The return of consciousness: a new science on old questions. Stockholm: Axel and Margaret Axson Johnson Foundation, 2017. p. 125-143.

WILLIFORD, K.; RUDRAUF, D.; LANDINI, G. The paradoxes of subjectivity and the projective structure of consciousness. In: MIGUENS, S.; PREYER, G. (ed.). Consciousness and subjectivity. Frankfurt a. M.: Ontos, 2012. p. 47-321.

Recebido: $15 / 11 / 2018$

Aceito: $15 / 11 / 2018$ 